\title{
The Impact of US Nurses' Personal Religious and Spiritual Beliefs on Their Mental Well-Being and Burnout: A Path Analysis
}

\author{
Stephanie Harris ${ }^{1}$ (D) Hong Tao ${ }^{1}$
}

Accepted: 30 January 2021 / Published online: 25 February 2021

(c) The Author(s), under exclusive licence to Springer Science+Business Media, LLC part of Springer Nature 2021

\begin{abstract}
This study addresses the gap in the literature regarding the impact of nurses' personal religious and spiritual beliefs on their mental well-being and burnout. A model of the association between these factors was tested based on surveys of 207 nurses located in southeastern USA and analyzed to determine the association between religion/spirituality, mental well-being, and burnout. A path analysis supported a model in which, through its positive impact on mental well-being, religion/ spirituality was negatively associated with emotional exhaustion and depersonalization and positively associated with personal accomplishment.
\end{abstract}

Keywords Religion $\cdot$ Spirituality $\cdot$ Mental well-being $\cdot$ Burnout $\cdot$ Nurses

\section{Introduction}

Healthcare organizations are eager to improve the mental well-being of nurses because such actions support the Quadruple Aim to improve staff engagement and promote joy in practice (Bodenheimer and Sinsky 2014). Nurses experience tremendous stress in their jobs in direct care as evidenced by escalating reports of depression, compassion fatigue, and secondary trauma (Kelly 2020; Letvak et al. 2012; Nolte et al. 2017). Nursing burnout is an increasingly prevalent problem that has personal as well as patient safety implications (Hall et al. 2016; Medicine, National Academies of Sciences, \& Medicine 2019). In addition, burnout is associated with turnover in direct care nurses, and though estimates of turnover vary, it has been reported that over 19\% of nurses leave their positions annually (NSI Nursing

Stephanie Harris

Stephanie.Harris@adventhealth.com

Hong Tao

Hong.Tao@adventhealth.com

1 Center for Whole-Person Research, AdventHealth, 301 E. Princeton Street, Orlando, FL 32804, USA 
Solutions 2019). Thus, organizations must focus strongly on prevention and mitigation of burnout and related conditions. While many interventions focus on reducing stressors and building resilience (Magtibay et al. 2017; Sarazine et al. 2020), few focus on improving overall mental well-being.

The literature on religion and spirituality $(\mathrm{r} / \mathrm{s})$ in nursing primarily focuses on the provision of spiritual care to patients (Mamier et al. 2019; Pike 2011; Taylor et al. 2014). Nurses' personal spirituality often is only considered as it affects the ability to comfortably and competently provide whole-person care to patients and families (Taylor et al. 2019). Nurses are expected to be spiritual care "generalists"-assessing and meeting patients' basic spiritual care needs (Donesky et al. 2020). While the importance of the spiritual needs of patients is understood, there has not been extensive research to date on the personal $\mathrm{r} / \mathrm{s}$ beliefs of nurses and its impact on their mental health outcomes.

The purpose of this analysis is to assess the current state of religion and spirituality in hospital-based nursing staff and to examine its associations with mental well-being and burnout. This whole-person assessment of nurses may inform future well-being strategies focused on faith-based interventions.

\section{Background}

Mental well-being is a complex construct that incorporates both hedonic and eudaemonic happiness. The former includes subjective happiness and avoidance of pain, while the latter focuses on personal attainment of purpose and meaning in life (Ryff and Keyes 1995). Ryff (1989) describes mental well-being as a eudaemonic construct with six dimensions, including self-acceptance, positive relations with others, autonomy, environmental mastery, purpose in life, and personal growth. These constructs in the workplace may be characterized as realization of personal values and meaning in and through work (Bartels et al. 2019; Lee 2015). Reports regarding clinical staff suggest that loss of meaning in work is one of the drivers of burnout in both physicians (Shanafelt 2009; Shanafelt and Noseworthy 2017) and nurses (Schadenhofer et al. 2018). Conversely, finding meaning in work has been associated with protective factors against workplace stress (Moreno-Milan et al. 2019).

Burnout is a major driver of poor well-being and is widespread in the nursing workforce, with conservative estimates of $30 \%$ of nurses experiencing one or more aspects of burnout (Canadas-De la Fuente et al. 2018; Gomez-Urquiza et al. 2017). A report from the National Academy of Medicine reports burnout rates of between 35 and 54\% among nurses and physicians. (National Academy of Medicine 2019) Burnout is a work-specific phenomenon characterized by emotional exhaustion, depersonalization, and a decreased sense of personal accomplishment (Maslach and Jackson 1981). Emotional exhaustion involves feeling overextended and psychologically under-resourced. Depersonalization is marked by indifference to care recipients and cynicism towards those being treated. Decreased personal accomplishment involves feelings of incompetence and decreased capacity to fulfill one's role.

Burnout is associated with symptoms and conditions inconsistent with wellbeing, including stress (Oyeleye et al. 2013), post-traumatic stress disorder (Mealer 
et al. 2009), anxiety (Colville et al. 2017), and depression (Garrouste-Orgeas et al. 2015). For nurses, burnout has been associated with higher patient infection rates (Cimiotti et al. 2012) and perception of lower perceived patient safety grades (Halbesleben et al. 2008).

Nurses with symptoms of burnout, like others in distress, often turn to religion and spirituality to make meaning out of stressors and threats (Park 2005a, b; Perera et al. 2018). In other clinical personnel, there is evidence of a negative association between spirituality and burnout, depression, and anxiety (Doolittle et al. 2013; Hsiao et al. 2012; Wachholtz and Rogoff 2013). Nurses have been reported to rely on r/s when coping directly with death and dying (Palmer Kelly et al. 2019).

There are no consensus definitions of r/s in the literature (Koenig 2015; McSherry and Cash 2004; Pike 2011). Hill et al. (2000) define spirituality as the search for the sacred, and religion as the means through which to search for the sacred. Koenig defines religion as "beliefs and practices related to the Transcendent" (Koenig 2015, p. 19). In contrast, a consensus definition formed by multidisciplinary health and spiritual care providers characterized spirituality as "a dynamic and intrinsic aspect of humanity through which persons seek ultimate meaning, purpose and transcendence, and experience relationship to self, family, others, community, society, nature, and the significant or sacred" (Puchalski et al. 2014, p. 646).

The literature reflects the positive relationship between $\mathrm{r} / \mathrm{s}$ beliefs and practices and mental well-being. There is a significant relationship between religiosity and measures of life satisfaction (Ellison 1991). In a large study of over one-million Americans, frequency of religious service attendance is positively associated with both affective and cognitive measures of well-being across religious traditions (Lim 2015). Ivtzan et al. (2013) measured religiousness and spirituality among 250 individuals of varying religions and reported those who self-identified as spiritual were more likely than those who were not spiritual to score higher on measures of selfactualization (Short Index of Self-Actualization) and presence of meaning in life (Meaning in Life Questionnaire) (Ivtzan et al. 2013).

Typically, the study of nursing mental health focuses on the negative-stress, compassion fatigue, and burnout. Literature regarding mental well-being in nurses is uncommon. Studies addressing positive psychological profiles in nurses often relate to workplace resilience and positive coping, both of which are associated with positive mental well-being (Gao et al. 2017; Gloria and Steinhardt 2016).

This study seeks to address the gap in the literature regarding nurses and their personal religious and spiritual beliefs and their impact on mental well-being and burnout. Based on summarizing the literature, we propose a model that posits positive $\mathrm{r} / \mathrm{s}$ beliefs impact mental well-being in nurses and that mental well-being impacts burnout scores. To test this model, a path analysis was conducted to determine the relationship between these variables. Ultimately, interventions that seek to address the whole person-mind, body, and spirit—may enable organizations to address determinants of nursing burnout and turnover. 


\section{Methods}

\section{Data Collection}

Data were collected via a confidential, web-based, survey of nurses in six faith-based community hospitals, all a part of a large non-profit health system headquartered in Florida, USA. Inclusion criteria consisted of the requirement to be a hospital-based nurse at one of the six identified hospitals_-including nurses at all levels of practice and job role- the ability to access the survey from a computer or mobile device, and ability to speak and understand English. Exclusion criteria included inability or unwillingness to complete the survey, and inability to speak or understand English. Nurses received an internally funded stipend of $\$ 50$, added to paychecks, for completing the surveys, which included a combined 154 questions. All non-demographic questions were mandatory. The health system's Institutional Review Board approved the study. The invitations, distributed by e-mail, explained the research and directed participants to links which opened to the informed consent, where they were offered the option to continue with the research or to decline participation. The survey itself comprised demographic questions and nine validated instruments. For this study, three of the instruments were used in the final analysis. The surveys were created and hosted using Formstack, a HIPAA-compliant web-based platform.

\section{Sample Size}

The minimum sample size for this study was established at 194 participants to detect a difference for the result variables, emotional exhaustion, depersonalization, and personal achievement based on power $=0.80$, beta $=0.20$, [alpha] $=0.05$, and a medium effect size. Invitations were mailed to 2267 nurses. The anticipated sample size was 200 , to account for missing or unusable data.

\section{Measures}

World Health Organization Quality of Life-Spirituality, Religion and Personal Beliefs (WHOQOL-SRPB) is a 32-item validated instrument that assesses eight facets of religion, spirituality, and personal beliefs as they impact quality of life (WHOQOL SRPB Group 2006). This instrument is an addition to the existing four-item spirituality facet in the WHOQOL-100 measure of quality of life. The WHOQOLSRPB facets include connectedness to a spiritual being, meaning of life, awe, wholeness \& integration, spiritual strength, inner peace/serenity/harmony, hope \& optimism, and faith. Each facet consists of four questions on a 5-point Likert scale, from the least extent to the most, and total domain scores range between 4 and 20. Strong internal consistency is reported (alpha $=0.91$ ).

There has been some criticism of the WHOQOL-SRPB as a measure of r/s due to the focus of several of its facets on psychological well-being (Moreira-Almeida and Koenig 2006). When utilizing the instrument in conjunction with mental health 
outcomes, Moreira-Almeida and Koenig question, "Is it not surprising that psychological health is correlated with...[itself]?" (Moreira-Almeida and Koenig 2006, p. 844), noting that only three of the eight facets on the WHOQOL-SRPB purportedly measure r/s (connectedness to a spiritual being, spiritual strength, and faith.) While the measure is intended to be an assessment of $\mathrm{r} / \mathrm{s}$ as it pertains to quality of life, and broadly worded for cross-cultural suitability (WHOQOL SRPB Group 2006), there likely may be conflation between the measures and the outcome.

Krägeloh et al. (2015) utilized data from a sample of 679 university students to provide evidence for a two-factor model for the WHOQOL-SRPB. The three facets identified by Moreira-Almeida and Koenig were strongly correlated with each other and particularly with the religion subscale of the Brief COPE (Carver 1997; Krägeloh 2011; Krägeloh et al. 2015). The model wherein facets loaded into the two factors of spiritual coping and spiritual quality of life presented the best fit (Krägeloh et al. 2015), with the three facets in question comprising the spiritual coping factor.

The three facets-faith, connectedness to a spiritual being, and spiritual strength-were utilized in this model as the measure of spirituality, religion, and personal belief as it impacts quality of life. This broad interpretation, as intended by the creators, incorporates $\mathrm{r} / \mathrm{s}$ coping as a meaning-making adaptation in the wake of threats and challenges (Park 2005b). Each of the three facets includes items that address coping, but their scope is beyond coping alone.

The faith facet is composed of four questions that explore the association between faith and well-being, comfort, strength, enjoyment of life. Spiritual strength items include: the extent to which strength is felt, presence during difficulties, and contribution to living better and feeling happy. Connectedness to a spiritual being measures helpfulness during difficulties, stress tolerance, understanding of others, and source of comfort. The Cronbach's alpha was calculated in this study. The result was very acceptable with 0.97 for the total 12 items, and $0.97,0.90$, and 0.98 for the connection to a higher being, strength, and faith facets, respectively.

The Warwick-Edinburgh Mental Well-being Scale (WEMWBS) is 14-item instrument of positively worded statements that measure mental well-being over the previous two weeks. It measures various aspects of affective and psychological wellbeing, including interpersonal relationships, healthy functioning, and happiness (Stewart-Brown et al. 2009; Tennant et al. 2007). The scale ranges from 1-5 with 1 indicating "none of the time" and 5 indicating "all of the time." Scores range from 14-70. The National Health Service (UK) utilizes the scores of 40 or lower and 59 or higher as cutoff scores (Taggart et al. 2015). Cronbach's alpha for student samples was 0.89 and 0.91 for the general population (Tennant et al. 2007). It was 0.95 for this RN population in this study.

The Maslach Burnout Inventory (MBI) (Maslach and Jackson 1981) is a selfreported measure of burnout on three scales: emotional exhaustion, depersonalization, and personal accomplishment. Higher scores in emotional exhaustion and depersonalization and lower scores in personal accomplishment indicate higher levels of burnout. The scales have been designed for use with specific audiences, and in this case, the Human Services Survey for Medical Personnel version of the MBI was used among clinical staff. It is a 22-item instrument, and Cronbach 
alphas are reported as 0.90 for emotional exhaustion, 0.79 for depersonalization, and 0.71 for Personal Accomplishment scales (Maslach et al. 2010). The Cronbach alpha in this study was 0.92 for emotional exhaustion, 0.74 for depersonalization, and 0.85 for Personal Accomplishment.

Analysis Data analysis was performed using SPSS 25 software (IBMCorp 2017). Once the data file was examined for accuracy, missing data, and outliers, descriptive statistics were used to describe the sample population. Since the dependent variables are not normally distributed, the Kruskal-Wallis one-way analysis of variance test, which is a rank-based nonparametric test, was conducted to determine if there were statistically significant differences in the study outcomes among categories of each demographic variable, i.e., to examine the difference in r/s, mental well-being, emotional exhaustion, depersonalization, and personal accomplishment by age, marital status, work area, years of nursing experience, degree, and religion. The variable religion was clustered to four categories—catholic, protestant, agnostic/atheist, and other-to represent the major religious classifications represented in this sample.

Based on the associations found in published literature between (1) r/s and mental well-being and (2) mental well-being and burnout, a path model was created to determine the nature of the relationships between these variables (Chang and Chan 2015; Koenig et al. 2012; Laurencelle et al. 2002; Lim 2015). Then, a path analysis (Mertler and Reinhart 2016) was conducted to test the proposed model presented in Fig. 1. Bivariate correlation coefficients were calculated to measure the strength of the association between pairs of variables. Specifically, Pearson product-moment correlation was used for pairs of continuous variables, while Spearman rank-order correlation was used for pairs of ordinal variables. Statistical significance was determined at the 0.05 level.

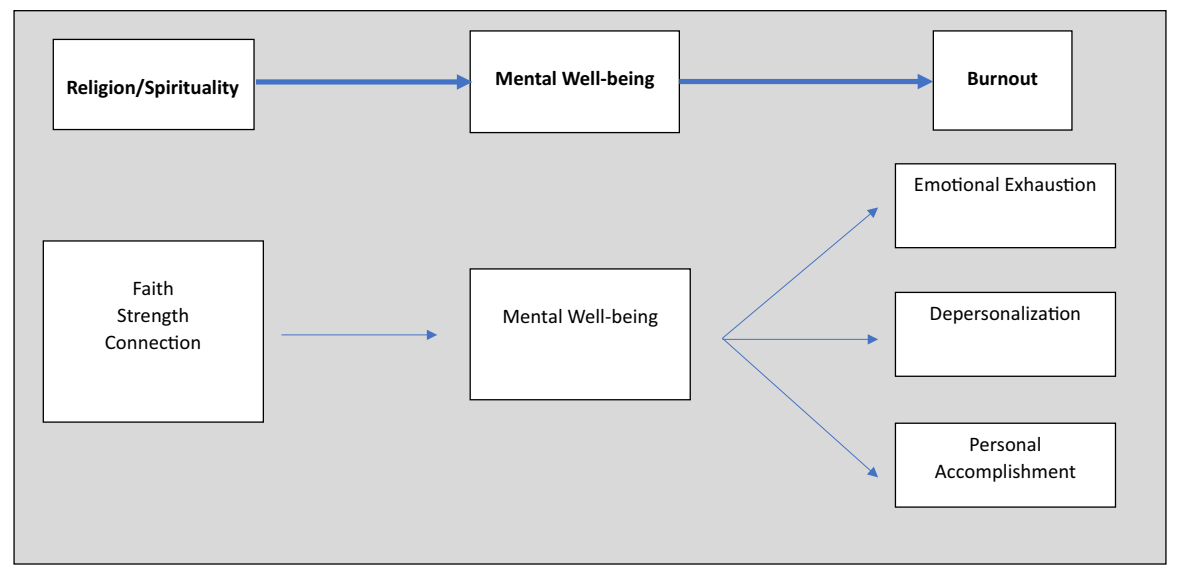

Fig. 1 A model of the association between religion/spirituality, mental well-being, and burnout. The top line consists of theoretical constructs, while the bottom line consists of the indicators for those constructs 


\section{Results}

The final sample was 207 nurses. There were no outliers identified through data cleaning. Since all questions except demographics were mandatory, there were no missing values. As indicated in Table 1, most nurses were white (79.7\%), and nurses aged 25-29 represented the largest percentage of the sample (17.9\%). Of the participants, $43.5 \%$ possessed at least 11 years of nursing experience, and $43.5 \%$ held bachelor's degrees as their highest degree, while $49.8 \%$ held associates degrees in nursing.. By work area, there were 114 acute care, 56 intensive care, and 37 ambulatory care nurses.

When asked to identify religious affiliation, $33.3 \%$ of nurses reported they were Christian or non-denominational, while $27.5 \%$ named a specific Protestant denomination; $25.6 \%$ of nurses identified as Catholic, $2.4 \%$ as Buddhist, and $0.5 \%$ as Jewish. Those who identified as agnostic/atheist were $7.2 \%$, and "other" included subject-provided answers, such as "I believe in God but do not associate with a religion" comprised $3.4 \%$ of the sample.

Table 2 presents the mean scores of r/s, mental well-being, and burnout, including emotional exhaustion, depersonalization, and personal accomplishment. Kruskal-Wallis one-way analysis of variance test reveals that except for $\mathrm{r} / \mathrm{s}$, all measures have significant results by comparison of demographic variables among groups. Intensive/critical care work area is associated with the highest depersonalization score $(M=6.23)$, and ambulatory care is associated with the lowest depersonalization score $(M=1.51)$. Having 2-5 years of experience is associated the highest emotional exhaustion score $(M=20.15)$ and the highest depersonalization score $(M=5.83)$. RNs who hold MSN/PhD/DNP degrees have the highest mental well-being score $(M=61.57)$, the lowest emotional exhaustion and depersonalization scores, and the highest personal accomplishment score $(M=6.64,0.57$, and 44.29, respectively). Finally, RNs who identify as Protestant as their religious affiliation have the lowest emotional exhaustion and depersonalization scores $(M=15.64$ and 3.69, respectively).

A path analysis was conducted to test the proposed model (Fig. 1), starting with including all the significant variables presented in Table 2 using linear regressions (stepwise). Prior to the analysis, outliers were checked, and no cases were removed. As shown in Fig. 2, the initial model (2a) includes a demographic variable, 2-5 years of RN experience, and a revised model (2b) is without this variable. All paths were significant at the 0.05 level. The initial model, presented in Fig. 2a, was not consistent with the empirical data. More specifically, four of the reproduced correlations exceeded a difference of 0.05. A revised model was generated by removing the variable, 2-5 years of RN experience. Calculation of reproduced correlations for the revised model indicated consistency with the empirical correlations as only one reproduced correlation exceeded a difference of 0.05 (see Table 3). All path coefficients were significant at the 0.01 level. The result demonstrates that in RNs, higher r/s has a positive impact on reducing burnout indirectly through an increase of their well-being. 
Table 1 Characteristics of 207 RNs

\begin{tabular}{lcc}
\hline & $N$ & $\%$ \\
\hline Age & & \\
$20-24$ & 8 & 3.9 \\
$25-29$ & 37 & 17.9 \\
$30-34$ & 27 & 13 \\
$35-39$ & 16 & 7.7 \\
$40-44$ & 24 & 11.6 \\
$45-49$ & 23 & 11.1 \\
$50-54$ & 23 & 11.1 \\
$55-59$ & 24 & 11.6 \\
$60+$ & 25 & 12.1
\end{tabular}

Race

American Indian or Alaska Native $\quad 6 \quad 2.9$

Asian

Black or African American

Multi-racial/multi-heritage

Native Hawaiian or other Pacific Islander

Other 4.8

White

Ethnicity

Hispanic or Latino

Non-Hispanic or Non-Latino

Marital status

Divorced

14.5

Married

Partnered

Separated

Single

19.8

Widowed

Work area

Ambulatory care

Intensive/critical care

Non-ICU acute care

Years of nursing experience

$\begin{array}{lll}0-1 & 19 & 9.2 \\ 2-5 & 52 & 25.1 \\ 6-10 & 46 & 22.2 \\ 11-20 & 31 & 15 \\ 21+ & 59 & 28.5\end{array}$

Highest degree

\begin{tabular}{lrr} 
AS & 103 & 49.8 \\
BSN & 90 & 43.5 \\
MSN & 11 & 5.3 \\
$\mathrm{PhD} / \mathrm{DPN}$ & 3 & 1.4 \\
\hline
\end{tabular}


Table 1 (continued)

\begin{tabular}{lrr}
\hline & $N$ & $\%$ \\
\hline Religion & & \\
Catholic & 53 & 25.6 \\
Protestant (named denomination) & 57 & 27.5 \\
Christian/non-denominational & 69 & 33.3 \\
Agnostic/atheist & 15 & 7.2 \\
Jewish & 1 & 0.5 \\
Buddhist & 6 & 2.4 \\
Other & 7 & 3.4 \\
\hline
\end{tabular}

\section{Discussion}

This cross-sectional study of community hospital nurses sought to determine the nature of the relationships between three combined facets of $\mathrm{r} / \mathrm{s}$ - faith, connectedness to a spiritual being, and spiritual strength-on mental well-being in nurses and the consequential impact on burnout. Surveys of 207 nurses indicated over $90 \%$ of nurses had a faith orientation and while $50 \%$ identified as religious, approximately $75 \%$ identified as spiritual. In addition, the survey revealed that nurses with 2-5 years of experience, those in intensive/critical care settings, and those without advanced degrees in nursing reported the highest levels of burnout.

Building from the foundation in the literature, which supports the associations between faith, mental well-being, and burnout, a path analysis was developed to better understand the nature of the relationship between these variables (Chang and Chan 2015; Koenig et al. 2012; Laurencelle et al. 2002; Lim 2015). The path analysis revealed a direct positive effect between $\mathrm{r} / \mathrm{s}$ and mental well-being and a direct negative effect of mental well-being on burnout, i.e., higher mental well-being was associated with lower burnout in the domains of emotional exhaustion, depersonalization, and higher scores in the domain of personal accomplishment.

\section{Burnout Levels in Terms of Experience, Setting, and Education}

The nurses in this study reported relatively low levels of burnout compared to other nursing samples, where published norms include means of 22.9 for emotional exhaustion (16.74 in this sample), 7.12 for depersonalization (4.44), and 36.53 for personal accomplishment (37.58) (Beckstead 2002). Given the prevalence of high levels of spirituality and lower burnout, personal spirituality may contribute to mental well-being such that it serves as a buffer against burnout. This model suggests that mental well-being mediates the association between $\mathrm{r} / \mathrm{s}$ and burnout.

In this study, early career nurses - those with two to five years of experiencedemonstrated the highest burnout in both the emotional exhaustion and depersonalization domains, which is consistent with studies of burnout in nurses during the first three years of practice (Rudman and Gustavsson 2011). 


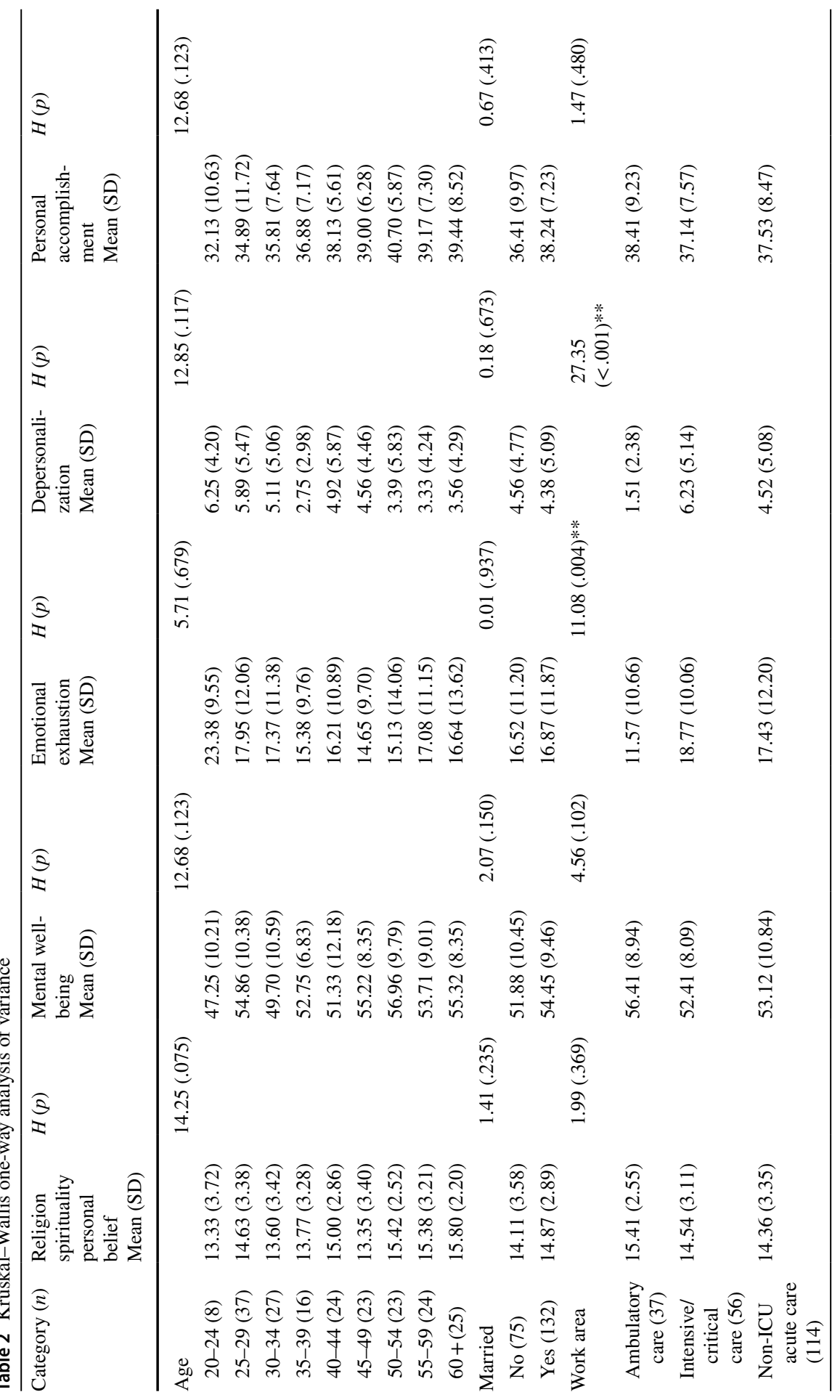




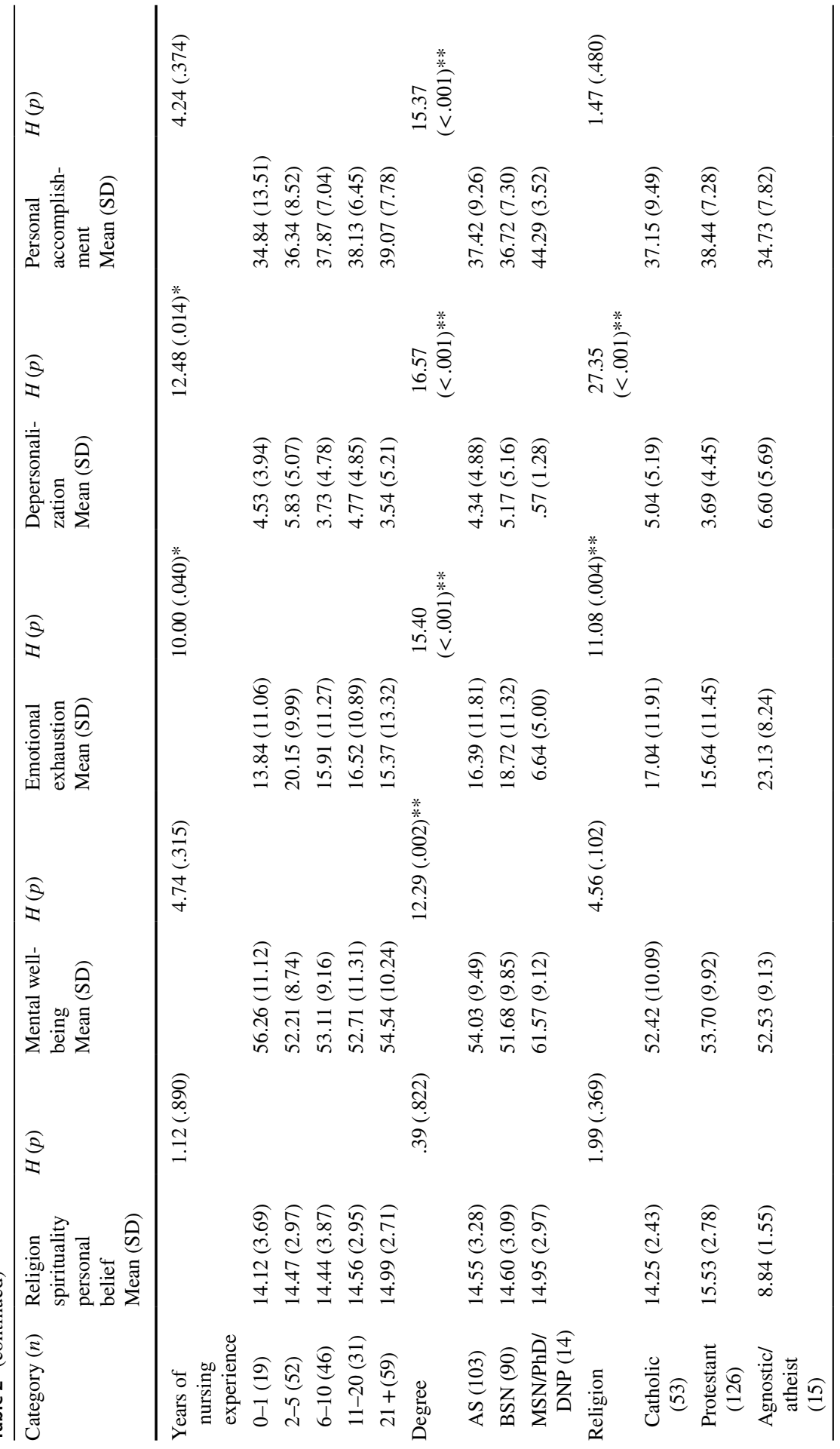




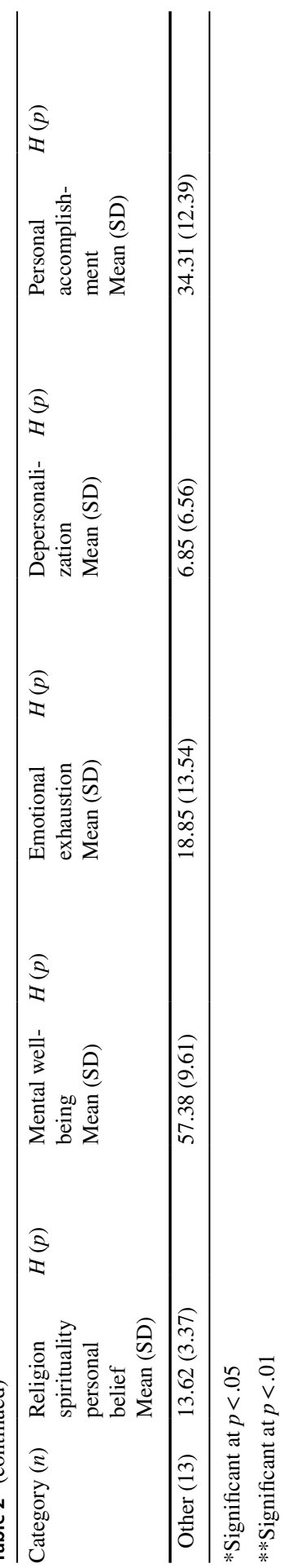




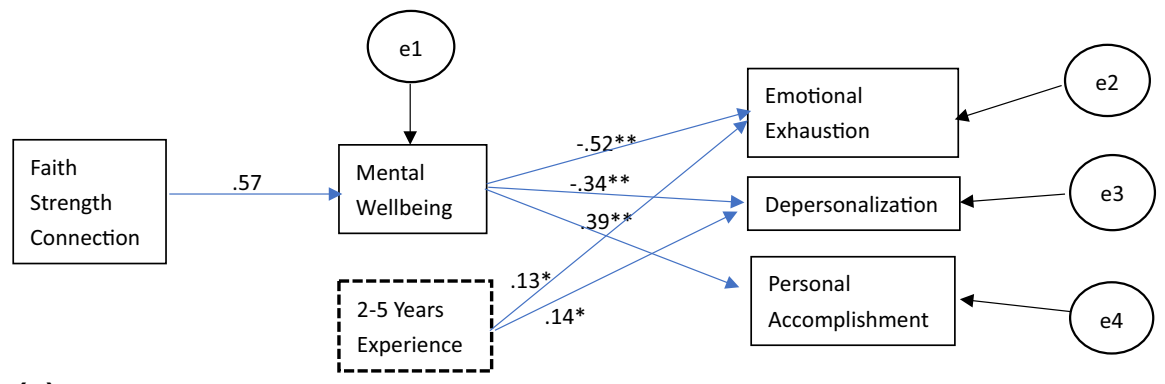

(a) Initial model

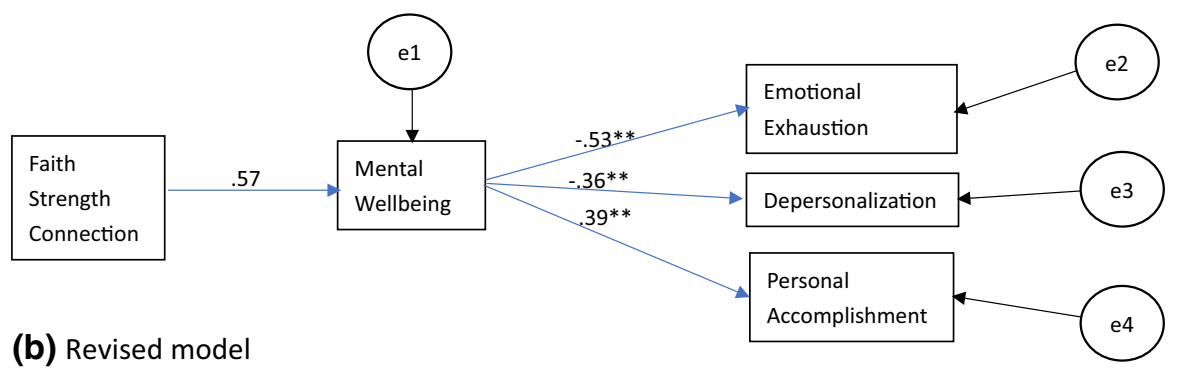

Fig. 2 Path diagram for initial and revised models including path coefficients. a Initial model, b revised model. $* p<0.05, * * p<0.01$

Table 3 Empirical and reproduced correlations for the initial model and the revised model

\begin{tabular}{lllll}
\hline & $\begin{array}{l}\text { Emotional } \\
\text { exhaustion }\end{array}$ & Depersonalization & $\begin{array}{l}\text { Personal accom- Mental well-being } \\
\text { plishment }\end{array}$ \\
\hline Mental well-being & -.53 & -.36 & .39 & \\
Religion/spirituality & -.30 & -.26 & .31 & .57 \\
2-5 years experience & .21 & .20 & $-.11^{\mathrm{a}}$ & $-.10^{\mathrm{a}}$ \\
& Reproduced correlations (initial model) & & \\
Mental well-being & -.52 & -.34 & .39 & .57 \\
Religion/spirituality & -.30 & $-.19^{\mathrm{b}}$ & $.22^{\mathrm{b}}$ & \\
2-5 years experience & $-.13^{\mathrm{b}}$ & $-.14^{\mathrm{b}}$ & & \\
& Reproduced correlations (revised model) & .39 & .57 \\
Mental well-being & -.53 & -.36 & $.22^{\mathrm{b}}$ & \\
Religion/spirituality & -.30 & -.21 & \multicolumn{5}{c}{} \\
\hline
\end{tabular}

${ }^{\mathrm{a}} p>0.05$

${ }^{\mathrm{b}}$ Difference between reproduced and observed correlation is greater than .05

Similarly, intensive/critical care nurses scored significantly higher in depersonalization and emotional exhaustion. Intensive care nurses face increased patient acuity, end-of-life issues, and moral distress associated with futile care (Mobley et al. 2007), and they experience increased levels of burnout as a result (Rushton et al. 
2015). Reinforcing mental well-being via a spiritually based intervention may be part of a multi-faceted approach to offer spiritual care to nurses in distress in high acuity areas.

Nurses with advanced degrees demonstrated the lowest levels of burnout in this study, as master's and doctorate-level nurses scored lower on emotional exhaustion and depersonalization, and higher in personal accomplishment. A study comparing burnout among nurse practitioners, nurse managers, and emergency nurses revealed that nurse practitioners have a greater sense of control and lower burnout than their counterparts (Browning et al. 2007). It is likely that nurses with more advanced degrees are in positions with more autonomy than that of a direct care nurse, e.g., nurse educator, and feelings of control over practice are related to lower burnout. Direct care nurses with associate and bachelor level degrees are more likely to benefit from interventions targeting mental well-being, as they experience less autonomy and higher burnout than nurses with more advanced degrees.

\section{Well-Being in Nursing}

The two-stage analysis indicates the impact from r/s to burnout is indirect through mental well-being; thus, it is essential to understand what mental well-being means in nurses. Mental well-being in clinical personnel is often discussed in terms of its absence rather than its presence. A systematic review of well-being in intensive care nurses yielded only four primary research papers (Jarden et al. 2020). While there are several studies on individual components of mental well-being in nurses, such as dispositional optimism (Chang and Chan 2015; Cruz et al. 2018), there is little on what constitutes mental well-being in a nursing population. This study supports integration of spirituality into the conceptualization of mental well-being in nurses and informs the creation of interventions to bolster mental well-being in this population.

Also, as discussed above, well-being consists of both hedonic and eudaemonic elements. In the case of nurses in a professional environment, eudaemonia may be achieved in part through finding meaning in work. Meaning in work may be defined as "the discovery of existential meaning from work experience, work itself, and work purpose/goals" (Lee 2015, p. 2263). Nursing is often regarded as a calling, i.e., a vocation with intrinsic motivation that verges on the religious (Emerson 2017). For some, this calling may be strictly internal, but for others there may be a sense of calling from a higher power. In nursing, it is possible for there to be a confluence of religion and work stemming from a higher sense of purpose and meaning.

Interventions that stress $\mathrm{r} / \mathrm{s}$ as a means of experiencing meaning in work and recognizing the calling to nursing may help to alleviate burnout through improved mental well-being.

The inverse relationship between mental well-being and emotional exhaustion and depersonalization signifies that a state of eudaemonic mental well-being may be protective against burnout. Conversely, a lack eudaemonic well-being may contribute to further burnout. For example, in physicians, spending less than $20 \%$ on meaningful activities was associated with higher odds of burnout (Shanafelt et al. 2009). Nurses likely face the same dilemma. A time motion study of medical-surgical 
nurses indicated they spent over $35 \%$ of time documenting and less than $20 \%$ of time directly caring for patients (Hendrich et al. 2008). This disconnect between what enables nurses to find meaning in work and their other responsibilities presents an opportunity for intervention on the part of hospitals and healthcare organizations.

\section{Implications for Nursing Practice, Education, and Research}

These findings present an opportunity to create meaningful spiritually based interventions for nurses. A systematic review and meta-analysis by Gonçalves et al. (2015) concluded that r/s-based interventions were associated with better mental health outcomes in both patients and healthy populations (Gonçalves et al. 2015). Consequently, these interventions would apply to nurses across the spectrum of mental and physical health conditions and burnout could be addressed in nurses anywhere on the emotional exhaustion and depersonalization continuum. Also, future research is needed to determine whether this model is applicable in non-faith-based organizations.

Due to high burnout in the early career stage of nursing, it would be advantageous to target nurses prior to this stage - either as students or new graduate nurses-with spiritually based interventions to bolster mental well-being as a burnout prevention strategy. This targeting could be integrated into a broader self-care strategy intended to increase retention in nurses with 2-5 years at the bedside, as up to one third of nurses leave direct care by the second year of nursing (Blegen et al. 2017; Kovner et al. 2014). Possible interventions include group orientation sessions co-facilitated by chaplains and licensed mental health professionals that discuss reconnecting to purpose and meaning in work, resilience, self-compassion, and stress recovery. The same can be applied to intensive/critical care nurses, who also scored significantly higher in depersonalization and emotional exhaustion.

\section{Implications for Nursing Administration and Policy}

Identification of the path from r/s to burnout through mental well-being is an important finding for health systems engaged in efforts to retain nurses at the bedside. Burnout is associated with turnover intent (Leiter and Maslach 2009), and mitigating burnout among nurses should be a key retention strategy. Targeting spirituality is a novel approach that may help nurses reconnect with meaning and increase their overall mental well-being. Spiritually based interventions are a part of a whole-person care strategy intended to improve mental well-being and consequently to reduce the prevalence of burnout.

\section{Limitations}

This study has several limitations, including the potentially tautological relationship between $\mathrm{r} / \mathrm{s}$ as it impacts quality of life and mental well-being. In measuring $\mathrm{r} / \mathrm{s}$, there has been wide criticism of the WHOQOL-SRPB by those who would argue that it is 
more a measure of psychological well-being than of spirituality; as such, the instrument was not used in its entirely and only three of eight facets were selected for analysis.

Additionally, the participants' demographics is a significant limitation as participants were self-selected from a relatively homogenous population from a group of community hospitals within the same faith-based healthcare organization. Therefore, this model is only applicable to those who identify as religious or spiritual and utilize r/s as a positive coping mechanism; those who use negative religious coping (i.e., God is punishing me) may not experience mental well-being associated with r/s.

Another limitation was study design, which was a cross-sectional survey of a convenience-based sample, and it did not differentiate job roles (e.g., managers, assistant managers) in analysis. In addition, all measures were self-reported, and thus, the data are limited by the weaknesses in this methodology. Some demographic variables, like age, were collected categorically for ease of user experience. Consequently, a nonparametric test was used in the analysis; collecting these data as a continuous variable would have strengthened the study. Finally, only one demographic variable was significant and retained in the initial model and further removed for the revised model. More variables that might contribute to the model need to be collected in the future studies.

\section{Conclusion}

This paper presents a model illustrating the positive association between religion/spirituality and mental well-being and the negative association between mental well-being and burnout in direct care nurses in a faith-based hospital system. Implications include an impetus for healthcare organizations to explore spiritually based interventions with nurses to promote mental well-being in a population that often suffers from burnout. Promoting mental well-being in the nursing workforce is both clinically and financially desirable, as nursing turnover is detrimental to patient care outcomes and the bottomline. An investment into the spiritual health of the nursing workforce-to reconnect nurses with meaning and purpose — may be part of a valuable retention.

\section{Compliance with Ethical Standards}

Conflict of interest The authors declare that they have no conflict of interest.

Ethical Approval The questionnaire and methodology for this study was approved by the Institutional Review Board at AdventHealth, IRB Number: 1462729.

Informed Consent Informed consent was obtained from all individual participants included in the study.

\section{References}

Bartels, A. L., Peterson, S. J., \& Reina, C. S. (2019). Understanding well-being at work: Development and validation of the eudaimonic workplace well-being scale. PLOS ONE, 14(4), e0215957. 
Beckstead, J. W. (2002). Confirmatory factor analysis of the Maslach Burnout Inventory among Florida nurses. International Journal of Nursing Studies, 39(8), 785-792.

Blegen, M. A., Spector, N., Lynn, M. R., Barnsteiner, J., \& Ulrich, B. T. (2017). Newly licensed RN retention: Hospital and nurse characteristics. Journal of Nursing Administration, 47(10), 508-514. https://doi.org/10.1097/nna.0000000000000523.

Bodenheimer, T., \& Sinsky, C. (2014). From triple to quadruple aim: Care of the patient requires care of the provider. The Annals of Family Medicine, 12(6), 573-576.

Browning, L., Ryan, C. S., Thomas, S., Greenberg, M., \& Rolniak, S. (2007). Nursing specialty and burnout. Psychol Health Med, 12(2), 248-254. https://doi.org/10.1080/13548500600568290.

Canadas-De la Fuente, G. A., Gomez-Urquiza, J. L., Ortega-Campos, E. M., Canadas, G. R., AlbendinGarcia, L., \& De la Fuente-Solana, E. I. (2018). Prevalence of burnout syndrome in oncology nursing: A meta-analytic study. Psychooncology, 27(5), 1426-1433. https://doi.org/10.1002/pon.4632.

Carver, C. S. (1997). You want to measure coping but your protocol' too long: Consider the brief cope. International Journal of Behavioral Medicine, 4(1), 92.

Chang, Y., \& Chan, H. J. (2015). Optimism and proactive coping in relation to burnout among nurses. Journal of Nursing Management, 23(3), 401-408.

Cimiotti, J. P., Aiken, L. H., Sloane, D. M., \& Wu, E. S. (2012). Nurse staffing, burnout, and health care-associated infection. American Journal of Infection Control, 40(6), 486-490. https://doi. org/10.1016/j.ajic.2012.02.029.

Colville, G. A., Smith, J. G., Brierley, J., Citron, K., Nguru, N. M., Shaunak, P. D., et al. (2017). Coping with staff burnout and work-related posttraumatic stress in intensive care. Pediatric Critical Care Medicine, 18(7), e267-e273. https://doi.org/10.1097/pcc.0000000000001179.

Cruz, J. P., Cabrera, D. N. C., Hufana, O. D., Alquwez, N., \& Almazan, J. (2018). Optimism, proactive coping and quality of life among nurses: A cross-sectional study. Journal of Clinical Nursing, 27(9-10), 2098-2108. https://doi.org/10.1111/jocn.14363.

Donesky, D., Sprague, E., \& Joseph, D. (2020). A new perspective on spiritual care: Collaborative chaplaincy and nursing practice. Advances in Nursing Science, 43(2), 147-158. https://doi.org/10.1097/ ans.0000000000000298.

Doolittle, B. R., Windish, D. M., \& Seelig, C. B. (2013). Burnout, coping, and spirituality among internal medicine resident physicians. Journal of Graduate Medical Education, 5(2), 257-261. https://doi. org/10.4300/jgme-d-12-00136.1.

Ellison, C. G. (1991). Religious involvement and subjective well-being. Journal of Health and Social Behavior, 32(1), 80-99.

Emerson, C. (2017). Calling to nursing: Concept analysis. Advances in Nursing Science, 40(4), 384-394. https://doi.org/10.1097/ANS.0000000000000185.

Gao, T., Ding, X., Chai, J., Zhang, Z., Zhang, H., Kong, Y., \& Mei, S. (2017). The influence of resilience on mental health: The role of general well-being. International Journal of Nursing Practice, 23(3), e12535. https://doi.org/10.1111/ijn.12535.

Garrouste-Orgeas, M., Perrin, M., Soufir, L., Vesin, A., Blot, F., Maxime, V., et al. (2015). The Iatroref study: Medical errors are associated with symptoms of depression in ICU staff but not burnout or safety culture. Intensive Care Medicine, 41(2), 273-284. https://doi.org/10.1007/s0013 4-014-3601-4.

Gloria, C. T., \& Steinhardt, M. A. (2016). Relationships among positive emotions, coping, resilience and mental health. Stress and Health, 32(2), 145-156.

Gomez-Urquiza, J. L., De la Fuente-Solana, E. I., Albendin-Garcia, L., Vargas-Pecino, C., Ortega-Campos, E. M., \& Canadas-De la Fuente, G. A. (2017). Prevalence of burnout syndrome in emergency nurses: A meta-analysis. Critical Care Nurse, 37(5), e1-e9. https://doi.org/10.4037/ccn2017508.

Gonçalves, J. P., Lucchetti, G., Menezes, P., \& Vallada, H. (2015). Religious and spiritual interventions in mental health care: A systematic review and meta-analysis of randomized controlled clinical trials. Psychological Medicine, 45(14), 2937-2949.

Halbesleben, J. R., Wakefield, B. J., Wakefield, D. S., \& Cooper, L. B. (2008). Nurse burnout and patient safety outcomes: Nurse safety perception versus reporting behavior. Western Journal of Nursing Research, 30(5), 560-577. https://doi.org/10.1177/0193945907311322.

Hall, L. H., Johnson, J., Watt, I., Tsipa, A., \& O’Connor, D. B. (2016). Healthcare staff wellbeing, burnout, and patient safety: A systematic review. PLOS ONE, 11(7), e0159015.

Hendrich, A., Chow, M. P., Skierczynski, B. A., \& Lu, Z. (2008). A 36-hospital time and motion study: How do medical-surgical nurses spend their time? The Permanente Journal, 12(3), 25. 
Hill, P. C., Pargament, K. I., Hood, R. W., McCullough, J., Michael, E., Swyers, J. P., et al. (2000). Conceptualizing religion and spirituality: Points of commonality, points of departure. Journal for the Theory of Social Behaviour, 30(1), 51-77.

Hsiao, Y. C., Wu, H. F., Chien, L. Y., Chiang, C. M., Hung, Y. H., \& Peng, P. H. (2012). The differences in spiritual health between non-depressed and depressed nurses. Journal of Clinical Nursing, 21(11-12), 1736-1745. https://doi.org/10.1111/j.1365-2702.2011.03962.x.

IBMCorp. (2017). IBM SPSS Statistics for Windows, Version 23. Armonk, NY.

Ivtzan, I., Chan, C. P., Gardner, H. E., \& Prashar, K. (2013). Linking religion and spirituality with psychological well-being: Examining self-actualisation, meaning in life, and personal growth initiative. Journal of Religion and Health, 52(3), 915-929.

Jarden, R. J., Sandham, M., Siegert, R. J., \& Koziol-McLain, J. (2020). Intensive care nurses' wellbeing: A systematic review. Australian Critical Care, 33(1), 106-111. https://doi.org/10.1016/j. aucc.2018.11.068.

Kelly, L. (2020). Burnout, compassion fatigue, and secondary trauma in nurses: Recognizing the occupational phenomenon and personal consequences of caregiving. Critical Care Nursing Quarterly, 43(1), 73-80. https://doi.org/10.1097/CNQ.0000000000000293.

Koenig, H. G. (2015). Religion, spirituality, and health: A review and update. Advances in Mind-Body Medicine, 29(3), 19-26.

Koenig, H., King, D., \& Carson, V. B. (2012). Handbook of Religion and Health (2nd ed.). Oxford: Oxford University Press.

Kovner, C. T., Brewer, C. S., Fatehi, F., \& Jun, J. (2014). What does nurse turnover rate mean and what is the rate? Policy, Politics, \& Nursing Practice, 15(3-4), 64-71. https://doi.org/10.1177/1527154414 547953.

Krägeloh, C. U. (2011). A systematic review of studies using the Brief COPE: Religious coping in factor analyses. Religions, 2(3), 216-246.

Krägeloh, C. U., Billington, D. R., Henning, M. A., \& Chai, P. P. M. (2015). Spiritual quality of life and spiritual coping: Evidence for a two-factor structure of the WHOQOL spirituality, religiousness, and personal beliefs module. Health and Quality of Life Outcomes, 13(1), 26.

Laurencelle, R. M., Abell, S. C., \& Schwartz, D. J. (2002). The relation between intrinsic religious faith and psychological well-being. The International Journal for the Psychology of Religion, 12(2), $109-123$.

Lee, S. (2015). A concept analysis of "Meaning in work" and its implications for nursing. Journal of Advanced Nursing, 71(10), 2258-2267. https://doi.org/10.1111/jan.12695.

Leiter, M. P., \& Maslach, C. (2009). Nurse turnover: the mediating role of burnout. Journal of Nursing Management, 17(3), 331-339. https://doi.org/10.1111/j.1365-2834.2009.01004.x.

Letvak, S., Ruhm, C. J., \& McCoy, T. (2012). Depression in hospital-employed nurses. Clinical Nurse Specialist, 26(3), 177-182. https://doi.org/10.1097/NUR.0b013e3182503ef0.

Lim, C. (2015). Religion and subjective well-being across religious traditions: Evidence from 1.3 million Americans. Journal for the Scientific Study of Religion, 54(4), 684-701.

Magtibay, D. L., Chesak, S. S., Coughlin, K., \& Sood, A. (2017). Decreasing stress and burnout in nurses: Efficacy of blended learning with stress management and resilience training program. JONA: The Journal of Nursing Administration, 47(7/8), 391-395.

Mamier, I., Taylor, E. J., \& Winslow, B. W. (2019). Nurse spiritual care: Prevalence and correlates. Western Journal of Nursing Research, 41(4), 537-554. https://doi.org/10.1177/0193945918776328.

Maslach, C., \& Jackson, S. E. (1981). The measurement of experienced burnout. Journal of Occupational Behavior, 2(2), 99-113. https://doi.org/10.1002/job.4030020205.

Maslach, C., Jackson, S. E., \& Leiter, M. P. (2010). Maslach burnout inventory: Manual (4th ed.). Menlo Park: Mind Garden.

McSherry, W., \& Cash, K. (2004). The language of spirituality: An emerging taxonomy. International Journal of Nursing Studies, 41(2), 151-161.

Mealer, M., Burnham, E. L., Goode, C. J., Rothbaum, B., \& Moss, M. (2009). The prevalence and impact of post traumatic stress disorder and burnout syndrome in nurses. Depress Anxiety, 26(12), 11181126. https://doi.org/10.1002/da.20631.

Medicine, National Academies of Sciences, \& Medicine. (2019). Taking action against clinician burnout: A systems approach to professional well-being. Washington, DC: The National Academies Press.

Mertler, C. A., \& Reinhart, R. V. (2016). Advanced and multivariate statistical methods: Practical application and interpretation. Milton Park: Taylor \& Francis. 
Mobley, M. J., Rady, M. Y., Verheijde, J. L., Patel, B., \& Larson, J. S. (2007). The relationship between moral distress and perception of futile care in the critical care unit. Intensive and Critical Care Nursing, 23(5), 256-263.

Moreira-Almeida, A., \& Koenig, H. G. (2006). Retaining the meaning of the words religiousness and spirituality: A commentary on the WHOQOL SRPB group's "a cross-cultural study of spirituality, religion, and personal beliefs as components of quality of life" (62: 6, 2005, 1486-1497). Social Science and Medicine, 63(4), 843-845. https://doi.org/10.1016/j.socscimed.2006.03.001.

Moreno-Milan, B., Cano-Vindel, A., Lopez-Doriga, P., Medrano, L. A., \& Breitbart, W. (2019). Meaning of work and personal protective factors among palliative care professionals. Palliative and Supportive Care, 17(4), 381-387. https://doi.org/10.1017/s147895151800113x.

National Academy of Medicine. (2019). Taking action against clinician burnout: A systems approach to professional well-being. Washington, DC: The National Academies Press.

Nolte, A. G. W., Downing, C., Temane, A., \& Hastings-Tolsma, M. (2017). Compassion fatigue in nurses: A metasynthesis. Journal of Clinical Nursing, 26(23-24), 4364-4378. https://doi.org/10.1111/ jocn. 13766 .

NSI Nursing Solutions, Inc. (2019). 2019 national healthcare retention \& RN staffing report. http://www. nsinursingsolutions.com/Files/assets/library/retention-institute/2019\%20National\%20Health\%20Car e\%20Retention\%20Report.pdf.

Oyeleye, O., Hanson, P., O’Connor, N., \& Dunn, D. (2013). Relationship of workplace incivility, stress, and burnout on nurses' turnover intentions and psychological empowerment. Journal of Nursing Administration, 43(10), 536-542. https://doi.org/10.1097/NNA.0b013e3182a3e8c9.

Palmer Kelly, E., Hyer, M., Payne, N., \& Pawlik, T. M. (2019). A mixed-methods approach to understanding the role of religion and spirituality in healthcare provider well-being. Psychology of Religion and Spirituality, 12(4), 487-493. https://doi.org/10.1037/rel0000297.

Park, C. L. (2005a). Religion and meaning. Handbook of the Psychology of Religion and Spirituality, 2, 357-379.

Park, C. L. (2005b). Religion as a meaning-making framework in coping with life stress. Journal of Social Issues, 61(4), 707-729.

Perera, C. K., Pandey, R., \& Srivastava, A. K. (2018). Role of religion and spirituality in stress management among nurses. Psychological Studies, 63(2), 187-199.

Pike, J. (2011). Spirituality in nursing: A systematic review of the literature from 2006-10. British Journal of Nursing, 20(12), 743-749. https://doi.org/10.12968/bjon.2011.20.12.743.

Puchalski, C. M., Vitillo, R., Hull, S. K., \& Reller, N. (2014). Improving the spiritual dimension of whole person care: Reaching national and international consensus. Journal of Palliative Medicine, 17(6), 642-656. https://doi.org/10.1089/jpm.2014.9427.

Rudman, A., \& Gustavsson, J. P. (2011). Early-career burnout among new graduate nurses: A prospective observational study of intra-individual change trajectories. International Journal of Nursing Studies, 48(3), 292-306. https://doi.org/10.1016/j.ijnurstu.2010.07.012.

Rushton, C. H., Batcheller, J., Schroeder, K., \& Donohue, P. (2015). Burnout and resilience among nurses practicing in high-intensity settings. American Journal of Critical Care, 24(5), 412-420. https://doi. org/10.4037/ajcc2015291.

Ryff, C. D. (1989). Happiness is everything, or is it? Explorations on the meaning of psychological wellbeing. Journal of Personality and Social Psychology, 57(6), 1069-1081.

Ryff, C. D., \& Keyes, C. L. M. (1995). The structure of psychological well-being revisited. Journal of Personality and Social Psychology, 69(4), 719.

Sarazine, J., Heitschmidt, M., Vondracek, H., Sarris, S., Marcincowski, N., \& Kleinpell, R. (2020). Mindfulness workshops effects on nurses' burnout, stress, and mindfulness skills. Holistic Nursing Practice. https://doi.org/10.1097/hnp.0000000000000378.

Schadenhofer, P., Kundi, M., Abrahamian, H., Blasche, G., Stummer, H., \& Kautzky-Willer, A. (2018). Job-related meaningfulness moderates the association between over-commitment and emotional exhaustion in nurses. Journal of Nursing Management, 26(7), 820-832.

Shanafelt, T. D. (2009). Enhancing meaning in work: a prescription for preventing physician burnout and promoting patient-centered care. The Journal of the American Medical Association (JAMA), 302(12), 1338-1340. https://doi.org/10.1001/jama.2009.1385.

Shanafelt, T. D., \& Noseworthy, J. H. (2017). Executive leadership and physician well-being: Nine organizational strategies to promote engagement and reduce burnout. Mayo Clinic Proceedings, 92(1), 129-146. https://doi.org/10.1016/j.mayocp.2016.10.004. 
Shanafelt, T. D., West, C. P., Sloan, J. A., Novotny, P. J., Poland, G. A., Menaker, R., et al. (2009). Career fit and burnout among academic faculty. Archives of Internal Medicine, 169(10), 990-995. https:// doi.org/10.1001/archinternmed.2009.70.

Stewart-Brown, S., Tennant, A., Tennant, R., Platt, S., Parkinson, J., \& Weich, S. (2009). Internal construct validity of the Warwick-Edinburgh Mental Well-being Scale (WEMWBS): A Rasch analysis using data from the Scottish Health Education Population Survey. Health and Quality of Life Outcomes, 7, 15. https://doi.org/10.1186/1477-7525-7-15.

Taggart, F., Stewart-Brown, S., \& Parkinson, J. (2015). Warwick-Edinburgh Mental Well-being Scale (WEMWBS). User guide-Version 2. Warwick Medical School, University of Warwick and NHS Scotland.

Taylor, E. J., Gober-Park, C., Schoonover-Shoffner, K., Mamier, I., Somaiya, C. K., \& Bahjri, K. (2019). Nurse religiosity and spiritual care: An online survey. Clinical Nurse Research, 28(5), 636-652. https://doi.org/10.1177/1054773817725869.

Taylor, E. J., Park, C. G., \& Pfeiffer, J. B. (2014). Nurse religiosity and spiritual care. Journal of Advanced Nursing, 70(11), 2612-2621. https://doi.org/10.1111/jan.12446.

Tennant, R., Hiller, L., Fishwick, R., Platt, S., Joseph, S., Weich, S., et al. (2007). The Warwick-Edinburgh Mental Well-being Scale (WEMWBS): Development and UK validation. Health and Quality of Life Outcomes, 5, 63. https://doi.org/10.1186/1477-7525-5-63.

Wachholtz, A., \& Rogoff, M. (2013). The relationship between spirituality and burnout among medical students. Journal of Contemporary Medical Education, 1(2), 83-91. https://doi.org/10.5455/ jcme.20130104060612.

WHOQOL SRPB Group. (2006). A cross-cultural study of spirituality, religion, and personal beliefs as components of quality of life. Social Science and Medicine, 62(6), 1486-1497. https://doi. org/10.1016/j.socscimed.2005.08.001.

Publisher's Note Springer Nature remains neutral with regard to jurisdictional claims in published maps and institutional affiliations. 